\title{
APLICAÇÕES DO MÉTOdO DE RIETVELD EM MINERALOGIA
}

\author{
F.M.S.Carvalho
}

D.Atencio

\section{INTRODUÇÃo}

O método de Rietveld tem sido considerado uma das principais ferramentas no estudo de estruturas cristalinas por difração de neutrons, hoje existindo, também, sua versão para difração de raios $X$ e para síncroton.

Rietveld $(1967,1969)$, preocupado com problemas relacionados a estudos de difração de neutrons, observou que, se fossem modelados os fatores instrumentais, seria possivel, então, refinar os parâmetros cristalográficos. A idéia foi rapidamente incorporada por pesquisadores que trabalhavam com difração de raios X. Malmros \& Thomas (1977) e Young et al. (1977) lançaram as primeiras versões do método aplicado à difração de raios $\mathrm{X}$, que tem sido aprimoradas até o presente. O método de Rietveld tem se popularizado com o aparecimento dos computadores pessoais, podendo-se encontrar um grande número de algoritmos espalhados pelo mundo. Alguns fabricantes de aparelhos de difração de raios $X$ (por exemplo, Philips e Siemens) já incluem versões do Método de Rietveld em seus pacotes de software.

\section{APLICAÇÓES}

Muitos mineralogistas já se depararam com problemas que só poderiam ser resolvidos por métodos cristalográficos relativamente complexos, que se utilizam de cristais únicos ou aplicam a difração de neutrons. Estes métodos necessitam, no primeiro caso, de cristais bem formados e com dimensões convenientes ou, no segundo, grande quantidade de amostra. A dificuldade de se obterem amostras com estas características é evidente em ambiente geológico, tornando muitos estudos impraticáveis. O método de Rietveld, apesar de não ser um método de resolução de estrutura propriamente dito, mas sim um método de refinamento, tem sido utilizado para

Departamento de Mineralogia e Petrologia, Instituto de Geociências, USP. 
determinar estruturas cristalinas por comparação com dados obtidos para compostos isomorfos, como mostram Post \& Bish (1989).

Para trabalhos mais simples, como o refinamento de parâmetros de cela, o método de Rietveld gera resultados mais precisos que os métodos convencionais.

Outra importante aplicação do método consiste na quantificação de misturas de fases cristalinas, sem o uso de padrōes externos ou internos, sendo muito eficiente para a maioria dos materiais, já se dispondo de programa especifico produzido pela Sietronics. Mais informações a respeito da aplicação do método para quantificação de fases podem ser encontradas em Snyder \& Bish (1989).

\section{A TÉCNICA}

A técnica aplicada, em resumo, consiste na procura do melhor ajuste entre um modelo calculado e os dados observados a partir de um diagrama de pó. 0 melhor ajuste é conseguido a partir do refinamento de parâmetros do equipamento, da preparação de amostras, e de dados do cristal (parâmetros de cela unitária, posições atômicas, fatores de temperatura e de ocupação atômica). A Figura 1 exemplifica um refinamento efetuado para o quartzo, onde foi obtido o melhor ajuste.

\section{PARÂMETROS REFINÁVEIS}

Diversos parâmetros podem ser refinados pelo método de Rietveld, entre os quais enumeram-se os seguintes: orientação preferencial, deslocamento do porta-amostra, transparência, absorção, background, assimetria do perfil, perfil instrumental, parâmetros atômicos, ocupação atômica, parâmetros de cela unitária, grau de cristalinidade, extinções sistemáticas e fator de escala.

\section{REQUISITOS BÁSICOS}

Para a aplicação do método de Rietveld, necessita-se de um difratômetro com motor de passo, possibilitando, assim, a digitalização dos dados para um microcomputador, ou um microdensitômetro para a digitalização de filmes. Uma boa preparação de amostra, de forma que sejam minimizados os efeitos de preparação, um equipamento bem calibrado e um modelo inicial próximos à realidade do material a ser estudado, além de um computador VAX ou PC (de preferência 386 ou superior, com coprocessador matemático) e um bom conhecimento dos efeitos instrumentais, de preparação e da estrutura cristalina que interferem no modelo são os principais requisitos para a aplicação do método de Rietveld. 


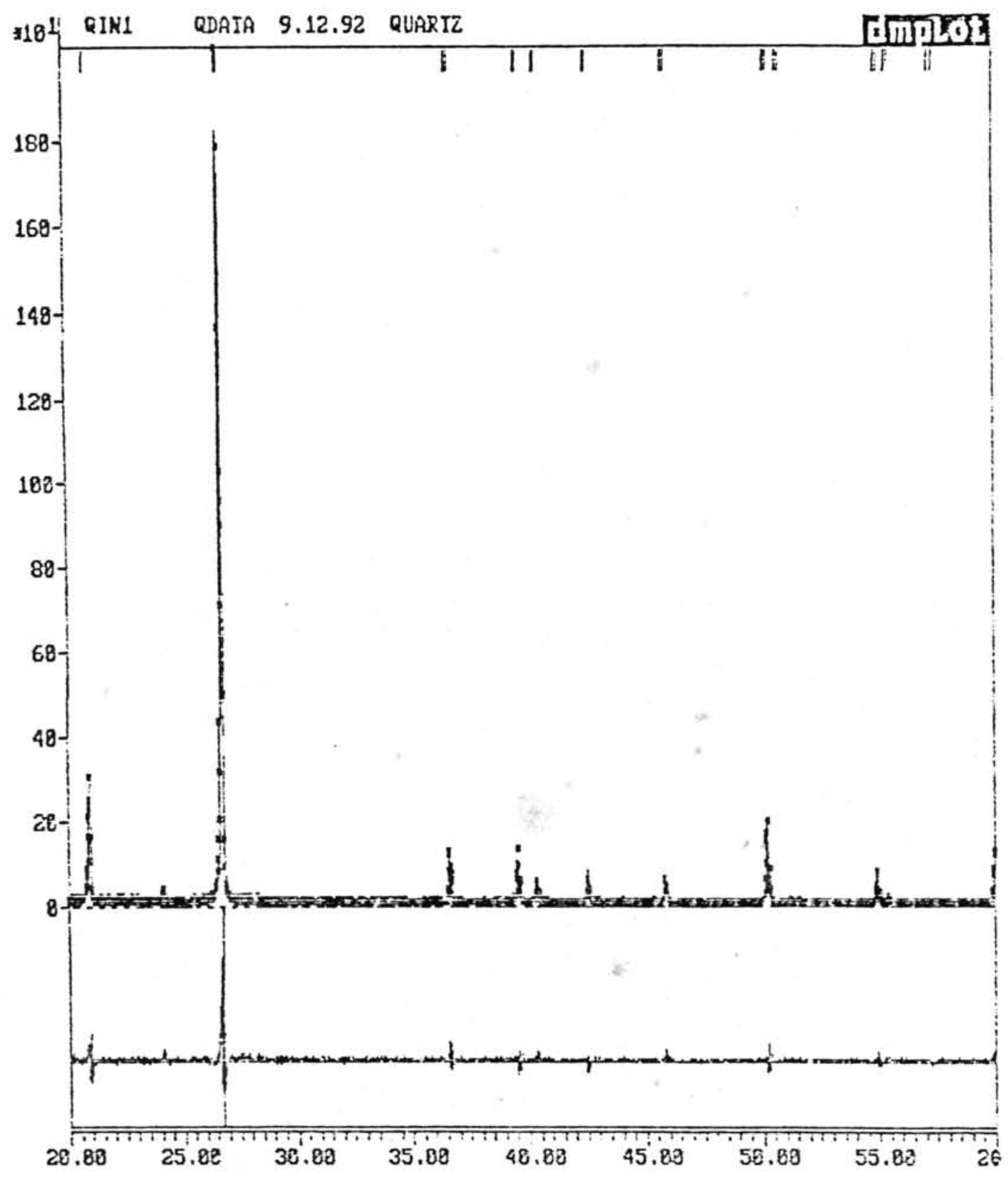

Figura 1 - Representação gráfica do método de Rietveld aplicado ao quartzo. A curva pontilhada representa os dados coletadios no difratômetro, a curva contínua representa a reprodução do modelo idealizado e refinado, a linha abaixo da linha de base representa a diferença entre os dados coletados e os dados medidos. 


\section{IMPLANTAÇÃO DO MÉTODO DE RIETVELD NO LABORATÓRIO DE DIFRATOMETRIA DE RAIOS X DO INSTITUTO DE GEOCIÊNCIAS DA USP}

O Laboratório de Difratometria de Raios X do Instituto de Geociências da USP possui cópia do programa DBWS 9006, gentilmente cedida pelo autor, Dr. Young durante a Second Rietveld Summer School, realizada no Instituto de Física da USP, em dezembro de 1992, organizada pela Sociedade Brasileira de Cristalografia. Mais detalhes a respeito deste software podem ser encontrados em Young (1992).

A partir deste programa, a técnica está sendo implantada no Laboratório, tanto instrumentalmente, quanto com relação à preparação de amostras, podendo, em curto espaço de tempo gerar os primeiros resultados.

\section{CONCLUSÕES}

O método de Rietveld mostra-se de grande importância para estudos mineralógicos, por permitir a obtenção de dados de estrutura cristalina a partir de pequenas quantidades de amostras policristalinas de minerais. Pode-se, entre outras coisas, quantificar fases cristalinas, calcular parâmetros de cela unitária, obter relações estequiométricas, posições atômicas. Apesar de os resultados obtidos não apresentarem a mesma precisão, até o momento, que aqueles oriundos de estudos por neutrons ou monocristal, pode-se atingir valores bastante satisfatórios.

\section{REFERÊNCIAS BIBLIOGRÁFICAS}

Malmros, G. \& Thomas, J.O. (1977) Least-square structure refinement based on profile analysis of film intensity data measured on an automatic micro densitometer. J. Appl. Cryst., 10:7-11.

Post, J.E. \& Bish, D.L. (1989) Rietveld refinement of crystal structures using powder X-ray difraction data. In: Bish, D.L. \& Post, J.E. (ed.) Modern Powder Diffraction. Rewiews in Mineralogy, 20:277308.

Rietveld, H.M. (1967) Line profiles of neutron powder-diffraction peaks for structure refinement. Acta Cryst., 22:151-152.

Rietveld, H.M. (1969) A profile refinement method for nuclear and magnetic structures. J. Appl. Cryst., 2:65-71.

Snyder, R.L. \& Bish, D.L. (1989) Quantitative Analysis. In: Bish, D.L. \& Post, J.E. (ed.) Modern Powder Diffraction. Rewiews in Mineralogy, 20:101-144.

Young, R.A.; MacKie, P.E.; Von Dreele, R.B. (1977) Application of the pattern-fitting structure-refinement method to X-ray powder diffractometer patterns. J. Appl. Cryst., 10:262-269.

Young, R.A. (ed.) (1992) The Rietveld Method. Oxford University Press (in press). 